\title{
ANALISIS TINGKAT KEPUASAN PENGUNJUNG TERHADAP KINERJA DAN TINGKAT KEPENTINGAN PENGUNJUNG PADA OBJEK WISATA AGRO HORTIMART AGRO CENTER BAWEN, KABUPATEN SEMARANG
}

\author{
ANALYSIS OF VISITOR SATISFACTION LEVELS ON PERFORMANCE AND \\ INTEREST OF VISITORS AT AGRO HORTIMART AGRO CENTER BAWEN \\ TOURISM OBJECT, SEMARANG REGENCY
}

\author{
Trie Venny Pratiwi ${ }^{1)}$ and Yuliawati ${ }^{1)}$ \\ Universitas Kristen Satya Wacana \\ Email: 522014019@student.uksw.edu
}

\begin{abstract}
ABSTRAK
Objek wisata agro adalah produk jasa yang ditawarkan oleh perusahaan untuk menarik banyak pengunjung. Penelitian ini bertujuan untuk menganalisis tingkat kepuasan pengunjung dengan tingkat kinerja dan kepuasan pengunjung terhadap Agro Hortimart Agro Center. Pendekatan yang digunakan adalah analisis deskriptif dengan metode survei dan kuesioner sebagai alat penelitian. Teknik pengambilan sampel menggunakan accidental sampling dengan 40 orang sebagai responden. Teknik analisis yang digunakan adalah analisis deskriptif, Importance Performance Analysis (IPA) dan Cartesian Diagram. Hasil analisis tingkat kepuasan pengunjung dengan metode Importance Performance Analysis (IPA) menunjukkan bahwa tingkat kinerja lebih tinggi dari kepentingan pengunjung (performance > importance) dengan skor rata-rata tingkat kinerja 4,06 dan skor rata-rata kunjungan pengunjung 4.02. Diagram kartesius menunjukkan bahwa kuadran I dan III membutuhkan perhatian khusus untuk menjaga dan meningkatkan kualitas layanan. Dengan demikian dapat disimpulkan bahwa pengunjung puas dengan kinerja yang dilakukan oleh Hortimart Agro Center.
\end{abstract}

Kata kunci: agrowisata, diagram kartesius, importance performance analysis (IPA), kepuasan pengunjung

\begin{abstract}
Agro tourism object is a service product offered by a company to attracts a lot of visitors. This study aims to analyze the level of visitor satisfaction with the level of performance and satisfaction of visitors to Agro Hortimart Agro Center. This approach uses descriptive analysis with a survey method that uses questionnaires as a research tool. The sampling technique used accidental sampling with 40 respondents. The analysis techniques used in this study are descriptive analysis, Importance Performance Analysis (IPA) and Cartesian Diagram. The results of the analysis of the level of visitor satisfaction with the Importance Performance Analysis (IPA) method indicate that the level of performance is higher than visitor performance (performance > importance) with an average score of performance level of 4.06 and an average score of visitor visits 4,02 . Cartesian diagrams show that I and III quadrants need special attention to keep and improve service quality. Thus it can be concluded that
\end{abstract}


visitors are satisfied with the performance carried out by the Hortimart Agro Center.

Keywords: agrotourism, cartesian diagram, importance performance analysis (ipa), visitor satisfaction

\section{PENDAHULUAN}

Indonesia merupakan salah satu negara beriklim tropis yang menjadi pusat keanekaragaman hayati terbesar dan memiliki berbagai jenis buah-buahan yang khas dari segi cita rasa, warna dan bentuk. Selain itu berbagai jenis tanaman seperti hortikultura dapat tumbuh subur. Di Indonesia industri pariwisata termasuk dalam kegiatan yang berperan menyumbangkan devisa bagi negara. Industri pariwisata juga berperan membuka ketersediaan lapangan kerja yang dapat mengurangi tingginya angka pengangguran di Indonesia. Pada tahun 2009, industri pariwisata berhasil menempati urutan ketiga dalam hal penyumbang devisa terbesar setelah komoditi migas dan minyak kelapa sawit di Indonesia (Sunarti, 2017).

Objek wisata agro merupakan suatu aktivitas wisata yang melibatkan penggunaan lahan pertanian serta segala fasilitas yang berhubungan yang saat ini lebih dikenal dengan agrowisata. Menurut Astuti (2014) agrowisata memiliki beragam variasi seperti agrowisata petik buah, memberi makan hewan ternak, labirin dari berbagai macam tanaman. Selain untuk sarana menikmati keindahan dan berekreasi, agrowisata juga merupakan sarana edukasi bagi para pengunjung. Contohnya dalam agrowisata petik buah, para pengunjung akan diajarkan cara memetik buah yang baik dan benar, serta kriteria matang buah yang tepat. Selain memberikan manfaat bagi pengunjung kegiatan tersebut juga memberikan manfaat bagi pihak agrowisata.

Upaya mewujudkan kepuasan pelanggan bukan hal yang mudah. Faktor utama penentu kepuasan pelanggan adalah persepsi pelanggan terhadap kualitas jasa tersebut. Upaya yang dapat dilakukan untuk memenuhi kepuasan pelanggan dapat dilakukan dengan berbagai strategi namun yang perlu dperhatikan 
kepuasan pelanggan merupakan strategi jangka panjang yang mana membutuhkan komitmen, baik yang menyangkut dana maupun menyangkut sumber daya manusia (Lupiyoadi, 2006). Pernyataan ini senada dengan pendapat Swasta (2000) bahwa salah satu faktor yang dapat membuat pelanggan puas adalah kualitas jasa. Dalam jangka panjang kualitas seperti ini memungkinkan perusahaan untuk memahami dengan seksama harapan serta kebutuhan konsumen. Dengan demikian pihak agrowisata dapat meningkatkan kepuasan konsumen dengan cara memaksimalkan pengalaman menyenangkan yang didapatkan oleh konsumen. Menurut Suryawan dan Dharmayanti (2013) kepuasan pelanggan adalah suatu persepsi yang ditentukan sendiri oleh pelanggan atas kinerja produk atau jasa yang dibeli. Kepuasan merupakan penilaian mengenai ciri atau keistimewaan produk atau jasa yang menyediakan tingkat kesenangan konsumen yang berkaitan dengan pemenuhan konsumsi konsumen. Kepuasan konsumen dapat diciptakan melalui kualitas layanan. Mutu suatu produk atau jasa secara langsung dipengaruhi oleh beberapa faktor yang dikenal dengan sembilan bidang dasar diantaranya ialah pasar, uang, manajemen, manusia, motivasi, bahan, mesin dan mekanisasi, metode informasi modern dan persyaratan prestasi yang lebih tinggi bagi produk (Tjandrawan, 2005). Kinerja adalah hasil kerja yang dicapai seorang pegawai dalam melaksanakan tugastugasnya atas kecakapan, usaha, pengalaman dan kesungguhan serta waktu menurut standar kriteria yang telah diterapkan sebelumnya. Tingkat kepentingan (importance) adalah evaluasi konsumen dalam menilai atribut yang terdapat di suatu objek agrowisata, yang meliputi asksesibilitas, sarana dan prasarana, fasilitas pendukung (Wirawan, 2009).

Berdasarkan kondisi terebut di atas, kualitas layanan berpengaruh terhadap kepuasan pengunjung agrowisata. Dengan demikian, penelitian ini akan membahas tentang analisis tingkat kepuasan pengunjung terhadap tingkat kinerja (performance) dan tingkat kepentingan pengunjung 
(importance) pada Objek Wisata Agro Hortimart Agro Center meliputi layanan yang diberikan dalam bentuk jasa maupun layanan yang berbentuk fisik seperti sarana prasarana dan fasilitas pendukung yang terdapat di Hortimart Agro Center.

\section{METODE PENELITIAN}

Penelitian dilakukan di Kabupaten Semarang tepatnya di Objek Wisata Agro Hortimart Agro Center beralamat di Jalan Gatot Subroto 55 Bawen. Pemilihan lokasi dilakukan secara purposive dengan pertimbangan Objek Wisata Agro Hortimart Agro Center terletak di lokasi srategis yaitu di jalan utama Solo-Semarang dan Jogja-Semarang. Penelitian dilakukan pada bulan April-Mei $2018 . \quad$ Penelitian menggunakan pendekatan deskriptif kuantitatif dengan metode survey yang menggunakan kuesioner sebagai alat penelitian. Teknik pengambilan sampel menggunakan accidental sampling dengan jumlah sampel sebanyak 40 orang. Data yang dikumpulkan terdiri dari data primer dan data sekunder. Data primer diperoleh dari hasil observasi lapangan dan pengamatan pada saat penelitian, serta dari hasil wawancara secara langsung dengan menggunakan kuesioner. Data sekunder diperoleh dari studi literatur pada buku, skripsi, jurnal dan internet.

Uji validitas dilakukan untuk memastikan seberapa baik suatu instrumen digunakan untuk mengukur konsep yang seharusnya diukur. Dalam praktiknya untuk menguji validitas suatu kuesioner menggunakan bantuan Microsoft Office Excel dan Statistical Product \& Service Solution (SPSS). Uji signifikansi dilakukan dengan membandingkan nilai $r_{\text {hitung }}$ dengan $r_{\text {tabel}}$, jika $r_{\text {hitung }}$ lebih besar dari $r_{\text {tabel }}$ dan nilainya positif maka butir pertanyaan atau pernyataan dinyatakan valid atau layak untuk digunakan dalam pengambilan data (Ghozali, 2005).

Reliabilitas menunjukkan bahwa suatu instrumen dapat digunakan sebagai alat pengumpul data karena insturmen tersebut baik dan memberikan hasil yang konsisten terhadap data yang dibutuhkan. Uji reliabilitas ini menggunakan teknik Croanbach alpha dengan bantuan 
Statistical Product \& Service Solution (SPSS), tujuannya untuk memberikan jaminan bahwa data yang diperoleh telah memenuhi kriteria untuk diuji dengan menggunakan metode yang ada. Instrumen yang dipakai dalam variabel dikatakan handal (reliabel) apabila memiliki nilai Croanbach alpha > 0,33 (Nasution, 2001).

Teknik analisis yang digunakan adalah analisis deskriptif, Importance Performance Analysis (IPA) dan Diagram Kartesius. Menurut Santoso (2011) tahapan pertama yang perlu dilakukan dalam metode Importance Performance Analysis (IPA) adalah menentukan tingkat kesesuaian antara tingkat kinerja dan tingkat kepentingan pengunjung atas kualitas dari atributatribut atau indikator yang diteliti melalui perbandingan skor tingkat kinerja dengan skor tingkat kepentingan pengunjung. Perbandingan skor tersebut didapatkan dari hasil penilaian yang dilakukan dengan mengunakan skala likert yaitu dengan skor 1 sampai 5 melalui program Statistical Product \& Service Solution (SPSS). Anggraini dkk. (2015) mengatakan bahwa kelebihan dari menggunakan metode importance performance analysis (IPA) adalah dapat menunjukkan hal apasaja yang perlu ditingkatkan atau dikurangi dari suatu atribut produk atau jasa untuk menjaga dan memenuhi keuasan pengunjung. Dalam menganalisis tingkat kepuasan pengunjung Objek Wisata Agro Hortimart Agro Center dengan menggunakan metode importance performance analysis (IPA) terdapat dua aspek yang diukur yaitu:

a. Performance (kinerja pelayanan) adalah evaluasi pengunjung terhadap kinerja perusahaan yang telah diterima pengunjung.

b. Importance (tingkat kepentingan pengunjung) adalah evaluasi konsumen dalam menilai atribut yang terdapat di Objek Wisata Agro Hortimart Agro Center .

Metode Importance Performance Analysis dari Cronin dan Taylor (1992) dirumuskan sebagai berikut: gap = Performance -

Importance

Keterangan:

a. Performance < Importance, berarti layanan yang diberikan 
kurang baik dan belum

1. Evaluasi

pengunjung memuaskan.

terhadap kinerja pegawai yang telah

b. Performance = Importance, berarti layanan yang diberikan masih normal dan telah memuaskan pengunjung.

c. Performance > Importance, berarti layanan yang diberikan sangat memperhatikan kepentingan pengunjung sekaligus sangat memuaskan pengunjung.

Menurut Supranto (2001) diagram kartesius merupakan diagram yang terdiri dari dua sumbu yang berpotongan yang terdiri dari sumbu $\mathrm{X}$ yang menunjukkan tingkat kinerja (Performance) dan sumbu Y yang menunjukkan tingkat kepentingan (Importance). Didalamnya terdapat empat kuadran yang setiap kuadrannya menunjukkan posisi dimensi kualias pelayaan yang diberikan oleh perusahaan kepada konsumen. Dalam menganalisis tingkat kepuasan pengunjung Objek Wisata Agro Hortimart Agro Center dengan menggunakan metode importance performance analysis terdapat dua aspek yang diukur yaitu: 
lingkungan, norma kesopanan bersifat relative di mana apa yang dianggap sebagai norma kesopanan berbeda di berbagai tempat, lingkungan dan waktu.

d. Kecekatan, berasal dari kata cekat yang berarti kecepatan, ketangkasan dalam mengerjakan sesuatu. Indikator ini digunakan sebagai alat untuk mengukur tingkat kepuasan pengujung terhadap kualitas layanan yang diberikan oleh pegawai saat melayani pengunjung.

e. Ketanggapan, berasal dari kata tanggap yang berarti suatu kebijakan untuk membantu dan memberikan layanan yang cepat dan tepat kepada pelanggan dalam penyampaian informasi maupun layanan memenuhi permintaan pengunjung lainnya.

f. Kesabaran, berasal dari kata sabar yang berarti bersikap tenang, tahan menghadapi cobaan, tidak lekas marah, tidak lekas putus asa, tidak tergesa dalam melakukan sesuatu. Indikator ini dapat mengetahui apakah para pegawai cukup sabar dalam melayani pengunjung yang berdampak pada kepuasan pengunjung Hortimart Agro

Center sendiri.

2. Evaluasi pengunjung terhadap kinerja perusahaan berupa atribut yang terdapat di Hortimart Agro Center. Indikator yang digunakan dalam penelitian ini adalah sebagai berikut:

a. Jalan di agrowisata merupakan sarana yang sangat penting karena merupakan akses yang dilalui oleh para pengunjung saat melakukan kegiatan wisata atau kunjungan dengan menggunakan kereta berkeliling kebun.

b. Kebersihan Agrowisata, selain jalan di agrowisata kebersihan agrowsiata menjadi sesuatu yang juga sangat penting demi kenyamanan pengunjung dan keindahan lokasi agrowisata.

c. Luas Area Parkir, sangat penting bagi suatu perusahaan jasa dibidang agrowisata untuk memperhatikan luas area parkir yang dimiliki apakah sudah cukup untuk menmpung seluruh kendaraan pengunjung mengingat semakin berkembangnya suatu usaha maka semakin banyak pula pengunjung yang datang. 
d. Ketersediaan toilet, toilet juga merupaka salah satu sarana yang penting karena kebanyakan orang akan membutuhkan toilet ketika bepergian.

e. Kenyaman menaiki kereta, kereta yang terdapat di Hortimart Agro Center disebut kereta bereliling kebun yang merupakan satu-satunya transportasi yang digunakan sebagai pengangkut pengunjung yang melakukan kegiatan wisata atau tour dengan kapasitas 12 orang pada setiap kereta.

f. Taman Bermain Anak, merupakan salah satu fasilitas tambahan yang disediakan oleh pihak Hortimart Agroo Center yang dapat digunakan oleh anakanak ketika menunggu giliran tour atau bahkan setelah melakukan kegiatan tour, terdapan beberapa sarana permainan anak diantaranya ayunan, papan jungkat jungkit, seluncur.

g. Ketersediaan Agro Resto, merupakan suatu sarana yang disediakan oleh pihak Hortimart Agro Center bagi para pengunjung yang ingin membeli makanan untuk dimakan ketika pengunjung merasa lapar setelah melakukan kegiatan wisata, agro resto juga dapat digunakan sebagai tempat melakukan reuni atau hal serupa karena memiliki tempat yang cukup luas.

h. Ketersediaan Agro Mart, merupakan tempat bagi para pengunjung yang ingin membeli sayur, buah atau oleh-oleh.

i. Program Wisata Hortimart, merupakan suatu rancangan kegiatan yang ditawarkan oleh pihak Hortimart Agro Center atau lebih dikenal dengan paket wisata.

\section{HASIL DAN PEMBAHASAN}

Berdasarkan hasil penelitian, rata-rata umur responden adalah 31,05 tahun dengan kisaran 17-50 tahun, sebanyak $87,5 \%$ berjenis kelamin perempuan dan $12,5 \%$ lakilaki. Berdasarkan jenis pekerjaan, $30 \%$ ibu rumah tangga, 22,5\% mahasiswa, $20 \%$ pegawai swasta, $15 \%$ guru, $5 \%$ pegawai negri, $2,5 \%$ pelajar. Berdasarkan alamat responden, sebanyak $62,5 \%$ pengunjung berasal dari luar Kabupaten Semarang sedangkan $37,5 \%$ berasal dari Kabupaten Semarang. Dengan demikian dapat 
disimpulkan bahwa rata-rata indek validitas secara umum pengunjung yang dijadikan sebagai responden adalah mayoritas perempuan yang berasal dari luar Kabupaten Semarang dengan pekerjaan adalah ibu rumah tangga.

\section{Hasil Uji Kualitas Data}

$\begin{array}{clr}\text { Hasil } & \text { uji } & \text { validitas } \\ \text { menunjukkan } & \text { seluruh } & \text { butir }\end{array}$
pernyataan yang diajukan kepada 40 responden dinyatakan valid dengan bergerak dari nilai terendah yaitu 0,621 sampai nilai tertinggi 0,988 . Hasil uji reliabilitas menunjukkan keseluruhan pernyataan yang digunakan dalam penelitian reliabel yang ditunjukkan oleh nilai koefisien alpha dengan nilai terendah sebesar 0,620 dengan nilai tertinggi 0,975 Nilai tersebut lebih besar dari nilai Croanbach alpha yang telah ditentukan yaitu sebesar 0,60.

\section{Analisis Tingkat Kepuasan Pengunjung Dengan Metode IPA (Importance Performance Analysis)}

Berdasarkan hasil analisis menggunakan metode IPA (Importance Performance Analysis) dapat dilihat pada tabel sebagai berikut:

Tabel 1. Hasil Analisis IPA Tingkat Kinerja dan Tingkat Kepentingan Pengunjung

\begin{tabular}{clccc}
\hline No & \multicolumn{1}{c}{ Indikator } & $\begin{array}{c}\text { Performance } \\
(\mathrm{X})\end{array}$ & $\begin{array}{c}\text { Importance } \\
(\mathrm{Y})\end{array}$ & Gap \\
\hline 1 & Keramahan & 4,16 & 4,15 & 0,01 \\
2 & Kerapian & 4,11 & 4,11 & 0,00 \\
3 & Kesopanan & 4,20 & 4,17 & 0,03 \\
4 & Kecekatan & 3,96 & 3,91 & 0,05 \\
5 & Ketanggapan & 4,06 & 4,07 & $-0,01$ \\
6 & Kesabaran & 4,02 & 3,97 & 0,05 \\
7 & Jalan di Agrowisata & 4,13 & 4,10 & 0,03 \\
8 & Kebersihan Agrowisata & 4,09 & 4,08 & 0,01 \\
9 & Luas Area Parkir & 4,04 & 4,00 & 0,04 \\
10 & Ketersediaan Toilet & 4,11 & 4,04 & 0,07 \\
11 & Kenyamanan Menaiki Kereta & 4,15 & 4,06 & 0,09 \\
12 & Taman Bermain Anak & 3,64 & 3,51 & 0,13 \\
13 & Ketersediaan Agroresto & 3,91 & 3,93 & $-0,02$ \\
14 & Ketersediaan Agromart & 4,02 & 3,93 & 0,09 \\
15 & Program wisata Hortimart & 4,04 & 4,01 & 0,03 \\
\hline & Rata-rata & 4,04 & 4,00 & 0,04 \\
\hline Sua & & &
\end{tabular}

Sumber: Analisis data primer, 2018 
Berdasarkan analisis dengan metode IPA yang ditunjukkan pada Tabel 1 secara umum terdapat perbedaan positif dari gap antara tingkat kinerja dengan tingkat keputusan pengunjung sebesar 0,04. Hal ini dapat diartikan bahwa tingkat kinerja yang dirasakan pengunjung lebih tinggi dari pada tingkat kepentingan pengunjung (performance > importance) yang ditunjukkan dengan nilai 4,04 > 4,00. Hasil tersebut menunjukkan bahwa pengunjung puas terhadap kinerja Hortimart Agro Center, sesuai dengan pendapat Cronin dan Taylor (1992) yang menyatakan bahwa jika Performance > Importance, berarti layanan yang diberikan sangat memperhatikan kepentingan pengunjung sekaligus sangat memuaskan pengunjung. Apabila dihubungkan antara tingkat kinerja dan tingkat kepentingan pengunjung terdapat kesenjangan, hal tersebut dapat dilihat dari rata-rata gap dengan skor 0,04, kesenjangan tersebut menunjukkan bahwa pengunjung puas karena nilai skor yang didapat adalah positif. Dengan hasil olah diagram kartesius dapat diketahui atribut yang terdapat pada kuadran 1 , kuadran 2, kuadran 3, dan kuadran 4 serta implementasi dari hasil tersebut. Atribut-yang terdapat pada masing-masing kuadran dapat dilihat pada Gambar 1 Diagram Pemetaan IPA berikut.

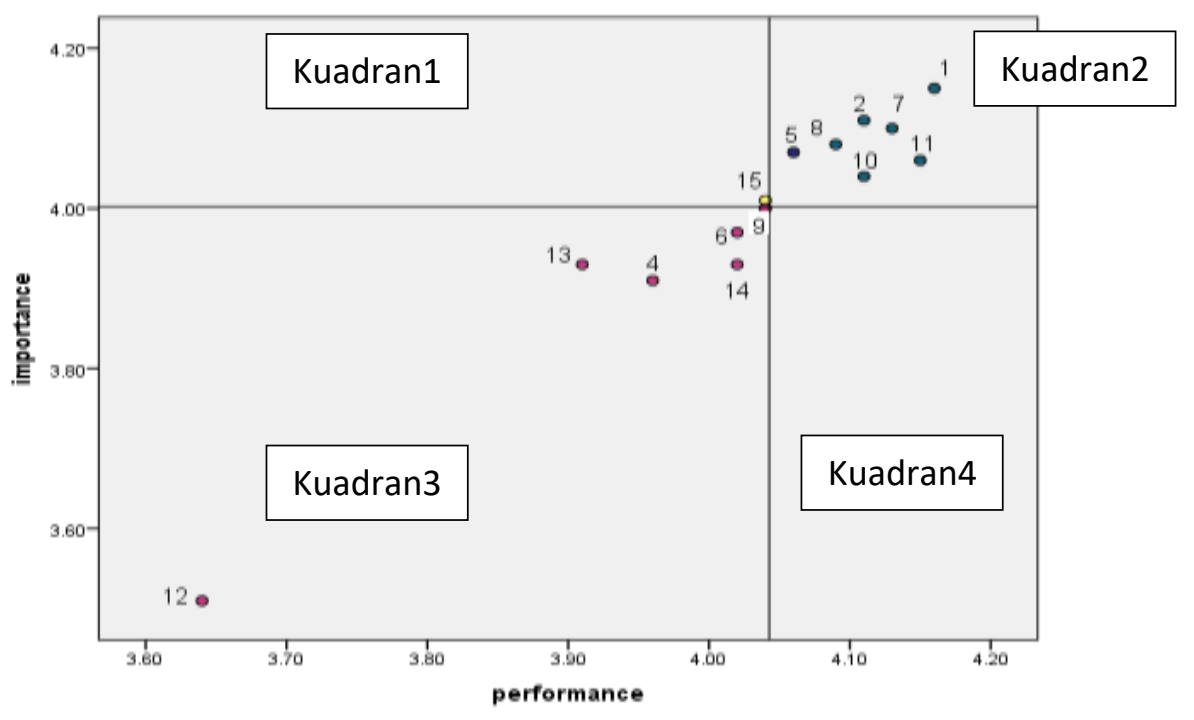

Gambar 1. Diagram Kartesius pemetaan IPA

(Sumber: Analisis data primer, 2018) 
Keterangan:

$\begin{array}{ll}1 & \text { Keramahan } \\ 2 & \text { Kerapian } \\ 3 & \text { Kesopanan } \\ 4 & \text { Kecekatan } \\ 5 & \text { Ketanggapan } \\ 6 & \text { Kesabaran } \\ 7 & \text { Jalan di Agrowisata } \\ 8 & \text { Kebersihan Agrowisata }\end{array}$

Berdasarkan pemetaaan IPA pada Gambar 1 dapat dijelaskan bahwa indikator yang perlu mendapatkan perhatian khusus serta peningkatan kualitas layanan ialah indikator yang berada pada kuadran I dan III. Kuadran I adalah kuadran yang menjadi prioritas utama dan indikator Program Wisata Hortimart berada pada kuadran ini, menunjukan bahwa Hortimart Agro Center harus memberikan perhatian lebih terhadap indikator ini dan juga meningkatkan kualitas layanan yang diberikan untuk memenuhi kepuasan pengunjung. Indikator pada kuadran I ini dianggap tingkat kepentingan (importance) nya sudah terpenuhi namun pada tingkat kinerjanya (performance) dianggap masih belum memenuhi kepuasan pengunjung.

Kuadran III dinilai belum bisa memenuhi kepuasan pengunjung baik dari segi tingkat kinerja (performance) maupun tingkat

\section{Luas Area Parkir}

Ketersediaan Toilet

Kenyamanan Menaiki Kereta

Taman Bermain Anak

Ketersediaan Agroresto

Ketersediaan Agromart

Program Wisata Hortimart kepentingannya (importance).

Indikator yang berada pada kuadran ini yaitu: kecekatan, kesabaran, luas area parkir, taman bermain anak, ketersediaan agroresto, ketersediaan agromart. Dengan demikian diharapkan pihak Hortimart Agro Center untuk memberikan perhatian dan meningkatkan kualitas pada indikator tersebut baik dari segi kinerja (performance) maupun tingkat kepentingan (importance) pengunjungnya demi memenuhi tingkat kepuasan pengunjung.

Hasil analisis secara keseluruhan pengunjung merasa puas berkunjung ke Hortimart Agro Center sehingga pihak Hortimart Agro Center harus mempertahankan kondisi ini dan senantiasa meningkatkan layanan yang diberikan. Oleh karena itu, pihak pengelola harus terus memantau dan membuka komunikasi dengan pengunjung sehingga didapatkan keselarasan antara keinginan 
pengunjung dengan pihak penyedia jasa. Dengan penelitian ini diharapkan pihak penyedia jasa maupun pihak pengunjung mampu bekerja sama dalam meningkatkan kualitas jasa secara berkelanjutan yang tentunya akan berpengaruh positif terhadap kenyamanan dan kepuasan yang terus-menerus diharapkan dapat menjadikan Hortimart Agro Center menjadi salah satu agrowisata yang menjadi tujuan wisata di Kabupaten Semarang serta Provinsi Jawa Tengah.

\section{KESIMPULAN DAN SARAN}

\section{Kesimpulan}

Dari hasil penelitian yang telah dilakukan, dapat disimpulkan bahwa pengunjung merasa puas terhadap tingkat kinerja dan tingkat kepentingan pengunjung yang diberikan oleh Hortimart Agro Center. Nilai rata-rata skor gap yang didapat menunjukkan nilai positif yaitu 0,04 menunjukkan bahwa terdapat kesesuaian antara kinerja dengan tingkat kepentingan pengunjung yang telah diberikan.

\section{Saran}

Berdasarkan hasil penelitian yang telah dilakukan di Hortimart Agro Center Bawen Kabupaten Semarang, maka saran yang dapat diberikan adalah:

1. Kecekatan dan kesabaran pegawai hortimart dalam melayani pengunjung harus ditingkatkan, luas area parkir lebih dipertimbangkan kembali untuk tahun-tahun berikutnya, taman bermain anak dibuat agar senyaman mungkin, ketersediaan agroresto dan agromart lebih diperhatikan kembali dari segi menu yang disediakan apakah sesuai dengan harga yang ditawarkan, program wisata hortimart ada baiknya ditambahkan paket atau kegiatan wisata yang baru.

2. Penelitian selanjutnya dapat melakukan penelitian berdasarkan divisi yang ada di Hortimart Agro Center, adapun divisi tersebut antara lain divisi agroestate, agroresto, agromart, agrotour dan agrosupply. 


\section{DAFTAR PUSTAKA}

Anggraini, L.D dkk. 2015. Analisis

Persepsi

Konsumen

Menggunakan

Importance

Metode

Analysis dan Customer

Satisfaction Index. Jurnal

Teknologi dan Manajemen

Agroindustri. 4(2):74-81.

Astuti, T.M. 2014. Potensi Agrowisata dalam

Meningkatkan Pengembangan

Pariwisata. Kementerian

Pariwisata dan Ekonomi

Kreatif. Jakarta. Jurnal JDP. 1(1).

Cronin, J.J dan S.A. Taylor. 1992. Measuring Service Quality: A Reexaminatiation and Extension. Journal of Marketing. Juny 56:55-68.

Ghozali, I. 2005. Aplikasi Analisis Multivariate Dengan Program SPSS. Program Magister Manajemen UNDIP. Semarang.

Lupiyoadi, R. 2006. Manajemen Pemasaran Jasa. Salemba Empat. Jakarta.

Nasution, M.N. 2001. Manajemen Mutu Terpadu. Ghulia Indonesia, Jakarta.

Santoso. 2011. Persepsi Konsumen Terhadap Kualitas Bakpao Telo dengan Metode Importance Performance Analysis (IPA). Jurnal Teknologi Pertanian. 12(1):9.

Supranto, J. 2001. Pengukuran Tingkat Kepuasan Pelanggan untuk Menaikkan Pangsa Pasar. Rineka Cipta. Jakarta.
Suryawan, S dan D. Dharmayanti. 2013. Analisis Hubungan Antara Experiental Marketing, Customer Satisfaction dan Customer Loyalty Café Nona Manis Grand City Mall Surabaya. Jurnal Manajemen Pemasaran. 2(3):3.

Sunarti, Dwi A.A. 2017. Pengaruh Kualitas Pelayanan Terhadap Kepuasan Konsumen (Survei pada Konsumen The Little A Coffe Sop Sidoarjo). Jurnal Administrasi Bisnis. 51(2).

Swasta, B. 2000. Asas-Asas Marketing. Liberty. Yogyakarta.

Tjandrawan, D.I. 2005. Total Quality Management Dalam Upaya Meningkatkan Mutu Produk, Guna Menunjang Aktivitas Perusahaan. Jurnal Manajemen Krida Wacana. 5(3): 165-180.

Wirawan. 2009. Evaluasi Kinerja Sumber Daya Manusia Teori Aplikasi dan Penelitian. Salemba Empat, Jakarta. 